\section{Andamios Revista de Investipación Social}

Andamios. Revista de Investigación Social ISSN: 1870-0063

revistaandamios@uacm.edu.mx

Universidad Autónoma de la Ciudad de México México

Kuri Pineda, Edith

El movimiento social de Atenco: Experiencia y construcción de sentido

Andamios. Revista de Investigación Social, vol. 7, núm. 14, septiembre-diciembre, 2010, pp. 321-345

Universidad Autónoma de la Ciudad de México

Distrito Federal, México

Disponible en: http://www.redalyc.org/articulo.oa?id=62819897013

- Cómo citar el artículo

Número completo

- Más información del artículo

- Página de la revista en redalyc.org

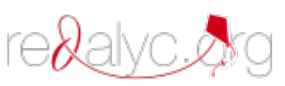

Sistema de Información Científica

Red de Revistas Científicas de América Latina, el Caribe, España y Portugal

Proyecto académico sin fines de lucro, desarrollado bajo la iniciativa de acceso abierto 


\title{
El movimiento social de Atenco: EXPERIENCIA Y CONSTRUCCIÓN DE SENTIDO
}

\author{
Edith Kuri Pineda*
}

\begin{abstract}
RESUMEN. En octubrede2001, el gobierno federal emitió diecinueve decretos expropiatorios con el propósito de construir un nuevo aeropuerto en la zona de Texcoco, estado de México. A esta decisión gubernamental se opuso un grupo de ejidatarios y residentes que erigieron el movimiento social de Atenco. En este artículo se analiza la dimensión interpretativa de la lucha atenquense, así como la importancia de la experiencia en el proceso constitutivo de este actor colectivo. Para tal efecto, se retoman algunas coordenadas heurísticas del historiador marxista E. P. Thompson, de Barrington Moore y de la denominada teoría del enmarcado.

Palabras Clave: Movimiento social, acción colectiva, experiencia, agravio, proceso de enmarcado.
\end{abstract}

Nuestras gentes son como lagartijas, van tomando el color dela tierra, semeten a laschozas dedondesalieron, vuelven a vestirse de peones y vuelven a esperar la hora de seguir peleando, aunque sea dentro de cien años.

CarlosFuentes

La solidaridad se basa en la rebelión, y la rebelión, a su vez, sólo puede encontrar su justificación en la solidaridad.

Albert Camus

* D octora en Sociología por la unam. Profesora adscrita a la Licenciatura en Sociología en la Universidad Autónoma Metropolitana-Azcapotzalco (UAM-A). Correo electrónico: kurichi1@hotmail.com.

Volumen 7, número 14, septiembre-diciembre, 2010, pp. 321-345

Andamios 321 
Edith Kuri Pineda

A MANERA DE PRESENTACIÓN: El DESARROLLO DEL CONFLICTO AEROPORTUARIO

Desde hace más de tres décadas, diversas voces de la clase política mexicana han señalado la necesidad de contar con una sede alterna al Aeropuerto Internacional Benito Juárez de la Ciudad de México. En 2001, el presidente panista Vicente Fox anunció que sería durante su gobierno cuando este proyecto sería concretado. Dos lugares fueron anunciados como posibles sedes de la nueva terminal aérea: Tizayuca en el estado de Hidalgo, y Texcoco en el estado de México.

Una vez dada a conocer esta noticia, surgieron en la opinión pública numerosas posturas sobre cuál de las dos candidaturas para construir el nuevo aeropuerto representaba la mejor alternativa en términos económicos, ecológicos, urbanísticos y aeronáuticos. Fue de ese modo que diversas instituciones educativas y gubernamentales realizaron estudios técnicos que tenían como finalidad evaluar el impacto regional que tendría dicho proyecto. Finalmente, el 22 de octubre de 2001, el gobierno federal dio a conocer que sería Texcoco la nueva sede de la terminal aérea; las razones que prontamente esgrimió se centraron en que esta zona mexiquense significaría una menor inversión económica además de supuestas ventajas aeronáuticas. La réplica a esta decisión, no obstante, no tardó en aparecer: varios especialistas subrayaron los riesgos demográficos, urbanísticos y ecológicos que la edificación aeroportuaria en Texcoco tenía, observaciones que tuvieron poco eco en los representantes gubernamentales.

De esta manera, tres municipios mexiquenses, Atenco, Chimalhuacán y Texcoco, con sus respectivas trece comunidades campesinas fueron afectados por los diecinueve decretos expropiatorios promulgados por el gobierno federal. ${ }^{1}$ El proyecto aeroportuario, sin duda el más ambicioso del sexenio foxista, contemplaba la inversión de capital privado hasta en un $75 \%$, del cual el $49 \%$ podía ser extranjero. Las 5,400 hectáreas expropiadas fueron valuadas en siete pesos el metro

\footnotetext{
${ }^{1}$ Del municipio de Texcoco: San Felipe, Santa Cruz, la Magdalena Panoaya, Santiago Cuauhutlalpan, Boyeros, Huexotla y Tocuila; de Atenco: San Salvador Atenco, Nexquipayac, Ixtapan y Acuexcómac; y del municipio de Chimalhuacán: la colonia Francisco I. Madero y Santa María Chimalhuacán.
} 
cuadrado para las tierras de temporal, mientras que las de riego fueron tasadas en 25 pesos el metro cuadrado. Cabe mencionar que todo el proceso decisorio sobre la sede aeroportuaria estuvo sellado por la arbitrariedad del gobierno federal, dado que jamás consultó ni informó consistentemente a las comunidades afectadas sobre las implicaciones que la edificación aeroportuaria tenía. Este hecho, junto con la baja tasación de estas tierras ejidales, propició que algunos actores políticos, como el Partido de la Revolución Democrática (PRD) - partido de centro izquierda fundado en 1989- así como el Gobierno del Distrito Federal, de extracción perredista, subrayaran las inconsistencias del manejo político que el gobierno del presidente Fox estaba realizando, situación que se mantuvo durante los nueve meses que duró el conflicto aeroportuario.

Pese a las voces críticas, el gobierno federal no cesó en subrayar que la construcción de la nueva terminal aérea representaría empleos y progreso para la zona mexiquense. Desde su perspectiva, el carácter salitroso de las tierras expropiadas, así como el poco arraigo de los pobladores de estas comunidades eran razones de sobra para echar andar el proyecto aeroportuario. Su ignorancia, o mejor dicho, su menosprecio a la historia de resistencia existente en esta región mexiquense, así como su falta de comprensión de una lógica construida socialmente a lo largo del tiempo, donde la tierra está al margen de las directrices del mercado, resultan evidentes. Un elemento digno de considerar sobre este punto, radica en que a lo largo de todo el conflicto, los ejidatarios y residentes movilizados en contra de la edificación de la nueva terminal aérea mantuvieron un rotundo rechazo a vender sus tierras. Subyacente a dicha decisión colectiva, se encontraba la defensa del centro, del sostén, de la vida material y simbólica de las comunidades: el territorio. Así, los diecinueve decretos expropiatorios representaron para los campesinos afectad os la amenaza contra un referente de identidad colectiva, a la vez fuente de trabajo y de sustento, y espacio de reproducción social y cultural.

Fue de este modo que irrumpió la movilización social en contra de la edificación aeroportuaria. Desde el inicio de este conflicto sociopolítico y jurídico, los pueblos de San Salvador Atenco, Acuexcómac, Tocuila, la colonia Francisco I. Madero y Nexquipayac desplegaron formas organizativas orientadas a echar abajo los diecinueve decretos expropiatorios. 
Edith Kuri Pineda

La comunidad de San Salvador Atenco se convirtió rápidamente en el núcleo de esta movilización colectiva; para el gobierno federal y el mexiquense este pueblo representaría, y sigue representando una expresión de rebeldía e ilegalidad, de una postura política radical encabezada por un grupo de "macheteros" que se oponían a la modernización del país.

Durante los nueve meses que duró el conflicto aeroportuario, la resistencia colectiva en contra de la construcción del aeropuerto tuvo dos frentes de lucha: la legal y la movilización social. La primera consistió en una serie de controversias constitucionales interpuestas por diversas comunidades afectadas por la expropiación, incluyendo el pueblo de San Salvador Atenco. El fundamento jurídico de estas acciones partió de las violaciones constitucionales en que el gobierno federal incurrió, al no sustentar jurídicamente la supuesta utilidad pública que la construcción de la nueva terminal aérea tendría, así como al no haber considerado a los gobiernos municipales en la decisión expropiatoria. Pese a estas medidas jurídicas, es importante señalar que la movilización social jamás cesó o estuvo condicionada a las acciones legales; por el contrario, para los ejidatarios organizados la acción colectiva siempre fue un espacio político prioritario, definitorio; para ellos, el descuido de este frente de lucha podía significar la expropiación de sus tierras, de ello siempre estuvieron ciertos los campesinos organizados. Tal como sostiene Alain Touraine:

La dimensión del conflicto es fundamental en todo movimiento social. Este conflicto puede ser parcialmente tratado en el nivel institucional, pero nunca por completo. Tal vez recurra a un árbitro, a un mediador o a los tribunales. Pero se trata de una táctica justificada tanto por la voluntad de utilizar los medios legales como por la fuerza para defenderse contra el adversario o atacarlo, y no de la convicción de que un cambio en la distribución de la influencia pueda hacer desaparecer la causa del conflicto. Por eso, sea cual sea su lugar particular de surgimiento, ese conflicto siempre es vivido por el movimiento social 
como un conflicto de clase. Afirmación que no se puede reducir a la idea de que todo movimiento social lucha por intereses económicos (1995: 251).

La articulación de los dos frentes de la lucha atenquense estuvo protagonizada por dos grupos existentes en el interior del movimiento: Atenco Unido y el Frente de Pueblos en Defensa de la Tierra (FPDT). EI primero, estaba formado por un grupo de hijos y nietos de ejidatarios cercanos al comisariado ejidal del pueblo de San Salvador Atenco, mientras que el segundo se constituyó en el grupo hegemónico de esta movilización campesina al paso de los meses. La diferencia entre ambos, radica en dos concepciones distintas sobre cuáles eran los espacios y las estrategias de defensa de la tierra: mientras que Atenco Unido priorizó las acciones jurídicas, el FPDT siempre consideró que la movilización era el mecanismo clave para echar abajo los decretos expropiatorios. Pese a estas notables diferencias políticas, resulta claro que ambos actores coincidieron en que la tierra debía ser defendida, en otras palabras: pese a la pluralidad constitutiva de este movimiento social, la tierra desempeñó el eje articulador de esta lucha.

En este sentido, los integrantes del FPDT desplegaron, durante los nueve meses de este conflicto sociopolítico y jurídico, un repertorio de confrontación ${ }^{2}$ - es decir formas de lucha- materializado en marchas, asambleas, bloqueos carreteros, barricadas, guardias y retención de funcionarios gubernamentales, es decir, diferentes modalidades de acción directa. El conflicto aeroportuario fue un intenso proceso de confrontación que marcó a las comunidades, de manera tal que los pueblos aún viven la división entre quienes decidieron participar en el movimiento y quienes estaban dispuestos a vender sus tierras. Para los campesinos que se opusieron al despojo de su patrimonio, la lucha se

\footnotetext{
${ }^{2}$ El término repertorio de confrontación es un concepto facturado por Charles Tilly y ha sido ampliamente retomado por diversos teóricos y estudiosos de los movimiento sociales y de la acción colectiva en general. Su relevancia heurística yace, como dice Sydney Tarrow, en ser "un concepto estructural y un concepto cultural [...] [ los repertorios de confrontación] no son sólo lo que hace la gente cuando entra en conflicto con otros; es lo que sabehacer y lo que los otros esperan que haga". Véanse Tilly (1978) y Tarrow (1997).
} 
Edith Kuri Pineda

fraguaba no sólo contra los policías que los golpeaban en las diversas marchas 0 en las estrategias políticas frente al adversario - el gobierno federal y el del estado de México- sino también con familiares, amigos 0 vecinos que se oponían al movimiento social. Finalmente, tras casi un año de enfrentamientos, en agosto de 2002, el gobierno federal decidió anular el proyecto aeroportuario. Pese a ello, la confrontación política tejida entre el FPDT y los actores gubernamentales continuó a partir de una nueva demanda que el actor atenquense enarboló: la anulación de todas las órdenes de aprehensión en contra de los integrantes de la resistencia. Asimismo, tras la abrogación de los decretos expropiatorios, el Frente decidió seguir erigiéndose como un actor sociopolítico a partir de un enorme desafío: la instauración de un concejo popular autónomo, el cual pretendía ser un ejercicio autogestivo, apartidista. Este proyecto finalmenteno funcionó, sin embargo su constitución fue un interesante ejercicio sociopolítico decidido en numerosas asambleas que, de nueva cuenta, marcó a las comunidades involucradas.

En este documento, se analizará cómo la acumulación de significados, experiencia y prácticas sociales constituye una veta sociológica clave para comprender el por quéy el cómo se construyó el movimiento atenquense. Para tal efecto, se revisarán algunos lineamientos teóricos de la denominada teoría del enmarcado (frame analysis), el concepto de experiencia y conciencia afectiva y moral del historiador inglés Edward Palmer Thompson, así como algunos planteamientos analíticos realizados por Barrington Moore.

\section{LA DIMENSIÓN INTERPRETATIVA DE LOS MOVIMIENTOS SOCIALES}

El movimiento social en contra de la edificación del aeropuerto ha sido objeto de diversas interpretaciones. Para algunos anal istas, la anulación de este proyecto por parte del gobierno federal, no es más que señal de debilidad en la aplicación de la ley o bien de ingobernabilidad ante la contundencia de un grupo de macheteros, tal como se ha denominado de forma despectiva a los integrantes del movimiento atenquense. Bajo esta lectura, sin duda elitista y limitada, estos ejidatarios 
no fueron más que un grupo de campesinos inconformes, manipulados por grupos políticos de "extrema peligrosidad". En otras palabras, Atenco se ha convertido en sinónimo de radicalidad e irracionalidad. Ya Antonio Gramsci, en los Cuadernos de la cárcel, hacía observaciones metodológicas y teóricas relativas al estudio de los grupos subalternos: "en vez de estudiar los orígenes de un acontecimiento colectivo, y las razones de su difusión, de su ser colectivo, se aislaba al protagonista y se limitaban a hacer su biografía patológica, demasiado a menudo tomando como base motivos no bien averiguados 0 interpretables en forma distinta: para una élite social, los elementos de los grupos subalternos tienen siempre algo de bárbaro y patológico" (Gramsci, 1981: 175).

Así, realizar un ejercicio comprensivo de la forma en que se construyen los actores colectivos exige rastrear aquellos factores históricos, culturales, políticos y sociales que de al guna forma los perfilan. Tal como dice Hugo Zemelman (1990), los sujetos sociales son condensadores de historicidad en dos sentidos: al ser fruto del pasado y como presente que contiene posibilidades de futuro. Partir de esta premisa epistemológica constituye una parte toral en el estudio de un fenómeno sociopolítico - como es el de la movilización social- que se distingue por su carácter multidimensional y por ser un proceso inacabado, un constructo social. Un elemento insoslayable al hablar de la forma en que se erigen los actores colectivos lo constituye el ejercicio interpretativo que los individuos hacen de su propia acción, en otras palabras, no hay acción colectiva sin intencionalidad, sin una cotidiana y compleja dinámica intersubjetiva de construcción de sentido, la cual, desde la perspectiva aquí asumida, puede ser estudiada a partir de un corte estrictamente analítico en dos planos:

- El que se da cara a cara entre los miembros de la movilización colectiva, en otros términos, el que es producto de un constante proceso de interacción subjetiva durante toda la dinámica de constitución y mantenimiento de la movilización social.

- El que se erige a partir del campo de confrontación construido por los sujetos colectivos y sus adversarios. 
Resulta claro que entre ambos niveles hay un nexo íntimo e indisociable: los integrantes de un movimiento social construyen significados sobre su lucha, sobre el nosotros y el ellos, en virtud de la relación que sostienen con su(s) adversario(s). Se trata, finalmente, de una dimensión relacional, en la que es a partir del conflicto, de las relaciones sociales de dominación, que los actores sociales se van constituyendo.

Es de esta manera que en los últimos años la teoría sobre los movimientos sociales ha orientado la mirada hacia la dimensión interpretativa que los integrantes de los actores colectivos despliegan en un escenario de organización y movilización. Un ejemplo claro de ello, es la llamada teoría del enmarcado (frame analysis), un sugerente enfoque analítico que lleva la impronta del trabajo sociológico de Erving Goffman. Según esta perspectiva de análisis, los marcos, son un conjunto de significados que inspiran y legitiman las acciones realizadas por los actores colectivos. En una coyuntura de movilización, los individuos identifican como problemáticas ciertas situaciones (marcos de diagnóstico), definen y deciden cuáles pueden ser las medidas para dirimir dicho problema (marcos de pronóstico), y construyen razonamientos que justifiquen la acción colectiva (marcos de motivos) (Hunt et. al.: 2006).

Este trabajo de definición de problemas y de identificación de los causantes de los mismos, supone una construcción social. Los marcos de diagnóstico, los marcos de pronóstico y los marcos de motivos, son erigidos intersubjetivamente de forma constante. Así pues, es posible afirmar que todo movimiento social es un agente productor de significados. En el interior de cada actor o sujeto colectivo, se vive una intensa dinámica de negociación sobre las formas de lucha y los posibles aliados, entre otros puntos. Reconocer lo anterior, implica concebir a la movilización colectiva no como un fenómeno acabado, cerrado, monolítico u homogéneo sino, por el contrario, como un proceso heterogéneo, rico y complejo que debe ser explicado sociológicamente. ${ }^{3}$

Dicho lo anterior, es posible preguntarse: ¿en qué se sustenta la interpretación realizada por los miembros de un actor colectivo? Parte

${ }^{3}$ Esta postura sociológica ha sido enarbolada, desde hace ya varios años, por diferentes teóricos de la acción colectiva, uno de los más destacados es Alberto M elucci. 
de la respuesta a esta interrogante radica en los propios referentes de significación de los actores sociales, o sea, a partir del entorno histórico, cultural, y vivencial, del cual todos somos, a un mismo tiempo, productores y producto. Al respecto, ahondan Scott, Benford y Snow:

La historia, las estructuras sociales y los condicionantes culturales determinan el trabajo interpretativo de los actores de los movimientos sociales. La forma en que estas "realidades" condicionan el trabajo interpretativo depende, sin embargo, de la forma en que esos actores perciban la historia, las estructuras sociales y los condicionamientos culturales. Determinadas pautas de acción colectiva surgen o no, no porque las condiciones objetivas las hagan posibles o las anulen, sino porque los seguidores de los movimientos perciben que esas condiciones "objetivas" permiten o impiden esas pautas de acción. En resumen, para entender la aparición de ciertas formas de acción colectiva, Ios analistas deben prestar atención a las definiciones intersubjetivas de la "realidad" que formulan los actores (Scott, Benford y Snow, 2006: 183-184). ${ }^{4}$

Un componente fundamental en el proceso de construcción de toda acción colectiva yace en que los individuos interpretan a partir del conjunto de experiencias vividas. Por lo tanto, es desde la sedimentación de experiencias y significados que los individuos (re)significan la realidad social. En el siguiente apartado, se verá de manera concreta cómo la experiencia vivida y resignificada individual y colectivamente desempeñó un papel medular en la constitución y mantenimiento de la lucha atenquense en contra del aeropuerto.

\footnotetext{
${ }^{4}$ De forma semejante a lo señalado por estos autores dice el sociólogo inglés Anthony Giddens: "La natural eza de un constreñimiento es históricamente variable como lo es la de las cual idades habilitadoras generadas por las contextual idades de una acción humana. Es variable en relación con las circunstancias materiales e institucionales de una actividad, pero también en relación con las formas de entendimiento que los agentes poseen acerca de sus circunstancias" (Giddens, 1984: 209).
} 
Edith KurI PInEda

\section{Atenco: experiencia politica}

Un elemento digno de considerar al hablar del proceso de enmarcado realizado por los movimientos sociales, lo constituye la forma en que éstos revelan, subrayan, circunstancias selladas por la injusticia que, antes de la irrupción colectiva, pasaban desapercibidas o bien habían sido "normalizadas" por diferentes sectores sociales. A este hecho, que sin duda resulta relevante, debe sumarse otro: toda lucha política es una lucha por el sentido. En el caso del conflicto aeroportuario, este aserto resulta claro y evidente: mientras el gobierno federal y el estatal preconizaron que la construcción de la nueva terminal aérea redundaría en el progreso y modernización de esta zona oriental mexiquense, los ejidatarios y residentes movilizados desarrollaron un discurso que enmarcaba el arraigo a la tierra, la defensa de una identidad campesina, así como la defensa de un patrimonio labrado gracias al trabajo individual y colectivo a lo largo del tiempo. En esta disputa política y semántica, los atenquenses organizados trataban de desacreditar la postura política y moral de sus adversarios, al mismo tiempo que buscaban autolegitimar su propia lucha.

La movilización en contra de los diecinueve decretos expropiatorios fue resultado de un proceso de deliberación colectiva, que se desplegó tanto en el plano legal como en el de la movilización social, tal como se señaló al inicio de este documento. Subyacente a este movimiento campesino, se encontraba una sedimentación de experiencias y saberes confeccionados en el propio territorio atenquense. Así, uno de los rasgos distintivos de la lucha en contra de la edificación aeroportuaria (sus repertorios de confrontación) no fue producto de la improvisación. En esta zona oriente del Estado de México existe una historia de organización y participación sociopolítica insoslayable que data de décadas atrás. América Del Valle, una de las figuras más destacadas del Frente de Pueblos en Defensa de la Tierra (FPDT), habla del anclaje histórico de la politicidad atenquense: ${ }^{5}$

\footnotetext{
${ }^{5}$ Es importante señalar que el presente artículo se sustenta en el trabajo de campo realizado a lo largo de un año en las comunidades de San Salvador Atenco, Acuexcómac y N exquipayac. Durante este tiempo se llevaron a cabo quince entrevistas a profundidad,
} 
Ya desde entonces, más allá de guardar las formas, de ir a pedirle el favor al gobierno, mandarle un escrito para ver si nos hacen caso, para ver que atiendan las demandas (sic) se echaba a andar la acción: Ia toma de carreteras, "que hay que ir a Toluca a bloquear", pues se iba, que había que ir a retener funcionarios para que nos escucharan [...]. Se daban situaciones donde la gente de muy bajos recursos llevaba a su familiar enfermo a un hospital privado - los públicos están de la fregada (sic) - y resultaba que la deuda se iba acumulando día tras día. ¿Y qué hacía la gente? Pues llegaban y sacaban a su familiar una vez que estuviera recuperado, todos iban de un jalón. Así que desde entonces creo que se fueron perfilando las formas de lucha, que van más allá de las tradicionales: hacer citas, armar una comisión, trámites, etcétera. Desde ahí entonces, se fueron perfilando las formas particulares que ha tenido Atenco para dar la lucha, arrancar los recursos que no son de nadie más que del pueblo. Me parece que esta etapa de cómo se fue conformando el Frente, tiene mucho que ver con el proceso que actualmente estamos vivien do [... ] (Del Valle, 2006).

De esta forma, existe un lazo histórico y político entre el Frente Popular Regional de Texcoco, el Frente Popular del Valle de México organización heredera de la primera - la agrupación Habitantes Unidos de San Salvador Atenco y lo que en los subsiguientes años será el FPDT, el cual, como se mencionó en páginas precedentes, fue el grupo hegemónico de la lucha en contra de la edificación de la nueva terminal aérea. En todos estos espacios de participación sociopolítica es posible abstraer aquellos rasgos definitorios de la politicidad atenquense: su carácter apartidista, su trabajo como gestor colectivo de distintas

semiestructuradas, a diversos integrantes del FPDT. En términos generales, las entrevistas estuvieron orientadas a conocer las formas organizativas y deliberativas, la construcción social de liderazgos, así como lo que significó para los miembros de este movimiento el haber participado en la lucha en contra de la expropiación. 
demandas sociales - vivienda, educación, salud- y la acción directa como una respuesta organizada frente a lo que los actores han leído como agravio, corrupción e incapacidad de los gobiernos locales. En consecuencia, estos antecedentes sociopolíticos representan una de las fuentes de experiencia política más notables en el interior de las comunidades, así como en la propia trayectoria de este actor colectivo.

Pese a esta historia de movilización social existente, resulta necesario señalar que en el seno de la lucha en contra del aeropuerto hubo un importante sector de ejidatarios y residentes que carecían de al gún tipo de experiencia política, ya fuera en partidos políticos o bien en algún movimiento u organización social. Este hecho, no obstante, no significa que dichos actores no tuviesen una experiencia organizativa labrada en el mismo marco de relaciones sociales intra, e intercomunitarias. Al respecto habla Ana María, integrante del FPDT, hija de un viejo ejidatario y con una nula experiencia política previa a la movilización en contra de los diecinueve decretos expropiatorios:

[... ] la organización de aquí es innata, es sorprendente [...] por ejemplo, si hay una fiesta cada quien llega desde un día antes a apoyar con lo que pueda o sepa hacer: lavar tomates, cocinar [...] todos preguntamos desde antes "¿qué se va a hacer?". Los señores casi siempre son de acomodar tamales (sic). Así, cuando llegamos al movimiento social, eso hicimos [...] (Robles, 2005).

Tal como el testimonio anterior posibilita ver, las fiestas constituyen una esfera de reproducción social, de organización colectiva y una fuente de identidad. San Salvador Atenco, junto con Nexquipayac, Acuexcómac, Tocuila - entre otras comunidades- son pueblos donde las fiestas católicas tienen un peso notable. La realización de cada una de ellas supone para el grueso de los pobladores la organización y diversificación de tareas, en resumidas cuentas, implica una red de colaboración intra e intercomunitaria, un entramado social de deberes y reciprocidades. Al igual que otros movimientos sociales latinoamericanos, en la lucha atenquense las relaciones sociales previas al conflicto desempeñaron un papel clave, como dice Raúl Zibechi: 
Es durante las grandes movilizaciones populares cuando los vínculos sociales entre los oprimidos, sumergidos en la cotidianeidad, se vuelven visibles al rasgar el velo de la indiferencia tejido por la opresión. En esos momentos, las relaciones sociales de reciprocidad urdidas durante largo tiempo en la sombra, en espacios lejos del control de los poderosos; salen a la luz del día, despliegan su potencia; el hacer cotidiano subterráneo se ventila entonces en el espacio público (Zibechi, 2005-2006: 42).

Otra fuente de experiencia organizativa para los miembros de la acción colectiva atenquense fue la transmitida por otros actores sociales - organizaciones y movimientos de diferente carácter sociopolítico- que durante el conflicto aeroportuario se solidarizaron con la lucha librada por ejidatarios y residentes en contra de la expropiación. ${ }^{6}$ Asimismo, es necesario señalar a aquellos integrantes del FPDT que contaban con otros marcos de experiencia organizativa y vivencial (como el del mundo obrero-sindical) que, siendo ejidatarios afectados por los decretos expropiatorios, decidieron defender sus parcelas ejidales.

En consecuencia, y recapitulando lo desarrollado a lo largo de este apartado, la experiencia política de al gunos miembros de la movilización atenquense, junto con la experiencia organizativa forjada en la fiestas y las faenas, además de la transmitida por otros actores sociales, constituyen las principales fuentes del acervo de conocimiento sociopolítico

\footnotetext{
${ }^{6}$ Como se sabe, todo movimiento social enfrenta, la gran mayoría de las ocasiones, a adversarios con un mayor poder político. Por lo tanto, las redes de alianzas que pueda entablar con otros actores resulta vital. En el caso del actor atenquense, una constelación de organizaciones y movimientos sociales se solidarizaron con él. Sólo por mencionar algunos de ellos: el Consejo General de Huelga (CGH); el Ejército Zapatista de Liberación Nacional (EzLn); integrantes del FrenteZapatista de Liberación Nacional; el Frente Popular Francisco Villa (FPFV); los campesinos organizados en contra de la construcción de un club de golf en Tepoztán, Morelos; miembros del movimiento de maestros rurales del Mexe de Hidalgo y de Morelos; Ia Unión Campesina Emiliano Zapata (UCEZ); sindicatos de Euzkadi, Ford y Fertinal; trabajadores y estudiantes de la U niversidad de Chapingo, así como organizaciones sociales, vecinales y estudiantiles de Veracruz, O axaca, Chiapas, Tlaxcala y Puebla.
} 
atenquense. ${ }^{7}$ Los diecinueve decretos expropiatorios emitidos por el gobierno federal el 22 de octubre de 2001, fueron una "prueba" para aquella acumulación de experiencia y saber pragmático, un conocimiento que posibilita que los individuos estemos habilitados para vivir y resolver los problemas del mundo social. Siguiendo la lógica interpretativa de Alfred Schutz, podemos sostener que la expropiación representó una "situación nueva" para miles de campesinos afectados, hecho ante el cual los atenquenses recurrieron a su acervo de conocimiento. En otras palabras, los decretos expropiatorios fueron un momento de crisis ante el cual fue preciso que los actores sociales (re)significaran todo lo aprendido para enfrentar dichas circunstancias. De este modo, los atenquenses decididos a defender la tierra (re)activaron aquellos sustratos de una memoria colectiva presente de diferentes maneras.

En esta misma tónica, resulta fundamental señalar la historia de despojo de tierras existente en esta región oriente del estado de M éxico. La experiencia vivida por aquellos campesinos cuyas tierras fueron expropiadas décadas atrás con la finalidad de construir la carretera Los Reyes-Lechería - donde la menguada indemnización llegó veintisiete años después- junto con el despojo vivido por ejidatarios del pueblo de Santa Isabel Ixtapan, ejemplificando, constituyen un memorial de despojo que, de cierta forma, condicionó la postura de aquellos atenquenses que decidieron defender su patrimonio una vez emitidos los decretos expropiatorios orientados a edificar la nueva terminal aérea en 2001.

Es de esta manera en que la experiencia constituye un factor clave para comprender una de las piezas centrales que conformaron al movimiento social de Atenco. En el debate teórico sostenido con Louis

\footnotetext{
7 Para Alfred Schutz y Thomas Luckmann: "el acervo de conocimiento del mundo de la vida se relaciona de muchas maneras con la situación del sujeto que vive la experiencia. Se erige sobre sedimentaciones de anteriores experiencias real mente presentes, vinculadas a situaciones. A la inversa, toda experiencia realmente presente se inserta en el fluir de vivencias en una biografía, según el conjunto de tipos y significatividades que se encuentran en el acervo de conocimiento. Y, final mente, cada situación es definida y dominada con ayuda del acervo de conocimiento, que así se vincula con la situación (es decir, la experiencia en cuanto ligada a la situación), tanto genética como estructural y funcionalmente" (Schutz y Luckmann, 1997: 109).
} 
Althusser, el historiador marxista Edward Palmer Thompson formuló algunos lineamientos analíticos:

En el campo de la experiencia hemos sido llevados a reexaminar todos los densos, complejos y elaborados sistemas mediante los cuales la vida familiar y social es estructurada y la conciencia social halla realización y expresión: parentesco, costumbre, las reglas visibles e invisibles de la regulación social, hegemonía y acatamiento, formas simbólicas de dominación y resistencia, fe religiosa e impulsos milenaristas, modos, leyes, instituciones e ideologías; todos ellos en conjunto, abarcan la genética del entero proceso social, agrupados todos, en un determinado punto, en la experiencia humana común [...] (Thompson, 1981: 262).

Hablar del concepto de experiencia nos exige encuadrarla cultural e históricamente. ${ }^{8}$ Toda experiencia es una condensación de elementos políticos, económicos, sociales y culturales. El hecho de que sea vivida y compartida intersubjetivamente le otorga un carácter colectivo, donde a pesar de que los actores se la apropian de forma particular - en función de sus propias historias personales- la resignifican como colectiva (como "mía" y como "nuestra"). Bajo esta perspectiva analítica, la experiencia colectiva es corporeizada de diferentes maneras: en recuerdos comunes, en prácticas sociales, en el lenguaje y en las mismas instituciones sociales y políticas.

La relevancia heurística del concepto de experiencia reside, desde nuestra postura interpretativa, en ser un factor de mediación entre estructuras sociales y la constitución de sujetos sociopolíticos. En el caso específico de la lucha en contra del aeropuerto, podemos señalar

\footnotetext{
${ }^{8}$ Como diceel historiador Adolfo Gilly en su interpretación del pensamiento deThompson: "la cultura se materializa en artefactos: ciudades, tecnologías, obras de arte, armas. Pero es la experiencia la que la preserva, la que la mantiene viva y la trasmite de generación en generación. Esta experiencia actúa a través de relaciones de poder, dominación y subordinación, hegemonía y resistencia y de permanentes negociaciones dentro de esas relaciones y contra ellas. Cada artefacto de cultura, visto de cerca, Ileva las huellas de esta experiencia social en su tiempo" (Gilly, 2006: 67).
} 
que la experiencia colectiva, las redes sociales preexistentes al conflicto aeroportuario, el hecho de que los decretos expropiatorios hayan sido interpretados, enmarcados, por los campesinos como un agravio, junto con el memorial de despojo existente, forman parte de aquellos factores de mediación. Dicho con otros términos, los elementos enunciados posibilitaron, en cierto modo, que el potencial de movilización se tornara en la misma acción colectiva.

Acentuar el peso de la experiencia en los procesos de movilización social nos conduce a enfatizar que aquella estará dotada de sentido, y en esa medida, orientará la acción sólo a partir del ejercicio interpretativo efectuado por los actores sociales. En resumen, los actores sociales reflexionamos sobre una vivencia pasada desde el presente, en otras palabras, no es posible hablar de experiencia sin una labor interpretativa. Los antecedentes de organización y participación sociopolítica, la existencia de redes sociales preexistentes al conflicto - algunas de ellas vinculadas con las fiestas religiosas y con las faenas- fueron espacios de experiencia fundamentales así como fuentes de identidad colectiva. Sin embargo, no hay que olvidar que la mera existencia de este movimiento social constituye otro espacio de experiencia colectiva medular el cual, hasta la fecha, ha marcado a las comunidades afectadas por la expropiación. Así pues, la experiencia de la lucha en contra de la nueva terminal aérea no sólo significó un parteaguas para aquellos atenquenses que decidieron defender la tierra, sino también para los propios adversarios de este actor colectivo, los priistas que pretendían vender sus parcelas. En todo este proceso social y político vivido en el interior de los pueblos, resulta claro que el conflicto aeroportuario significó para muchos de los atenquenses que decidieron participar en este movimiento social un enorme costo emocional. Al respecto da su testimonio Ana María, integrante del FPDT:

Fue una decepción, incluso con mi hermano el mayor, que era así como lo máximo, de pronto él estaba del otro lado, con los priistas. Me habló un día por teléfono y me dice (sic) que debo dejar de participar en el movimiento, yo le digo que no, le doy mis razones, él me da las suyas. Yo le contesté: "mira, no vamos a dejar de ser hermanos, 
respetemos nuestras ideas, ya somos mayores, si fuera una niña a lo mejor te decía que sí, pero ahora soy una adulta, puedo tomar decisiones, como hermanos nunca dejaremos de serlo, limitémonos a saludarnos y a ver como lo que somos (sic) y nada más". A partir de ahí, algo se rompió, la relación familiar, a mí me dolió mucho, son muchas cosas las que hemos vivido y tenemos que superarlo. En una reunión que de pronto se daba en la casa, con todos mis hermanos - de todos, siete estábamos en el movimiento- me dice uno: "¿Por qué Toño no está con nosotros, si él es el inteligente, el razonable? ¡Qué decepción de hermano!". Eso nos dolió mucho. [...] Otro era el concepto que teníamos de él [...] se rompió ese lazo (Robles, 2005).

Así, la dimensión emocional y moral es una veta de exploración empírica y analítica sin duda relevante al abordar el tema de los movimientos sociales. En el siguiente apartado se analiza la forma en que este plano se materializó en la lucha atenquense.

\section{EL ORIGEN DEL AGRAVIO}

Tal como se puede apreciar, el objetivo fundamental en el apartado precedente fue enfatizar cómo los movimientos sociales se construyen, también, a partir de la experiencia de sus integrantes, la cual siempre es social. Es a partir de la experiencia vivida, de aquellos referentes de significación delineados histórica, política y culturalmente, que los actores interpretan y construyen la realidad social; en otras palabras, es a partir de la acumulación de experiencias que los integrantes de los movimientos sociales enmarcan determinados hechos. En este sentido, el memorial de despojo y de agravios previo al conflicto aeroportuario conformó la savia que nutrió la interpretación de los ejidatarios y residentes afectados por los diecinueve decretos expropiatorios. Específicamente, la entrada de miembros de la policía estatal al pueblo de San Salvador Atenco en 1995 como resultado de la movilización entonces encabezada 
Edith Kuri Pineda

por Habitantes Unidos de San Salvador Atenco (HAUSA) - organización que en ese entonces demandaba mejor transporte, y que continuase el programa de tortibonos- así como las historias de despojo que circulaban en esta región del estado de México, fueron precedentes (re)significados por aquellos atenquenses que participaron en la lucha en contra del proyecto aeroportuario. El testimonio de América Del Valle ilustra lo señalado:

Creo que es un conocimiento que se va generando en la marcha, se va generando en ese proceso que además es, si tú quieres, un acumulado de experiencias porque tampoco hubiera sido lo mismo el movimiento en contra del aeropuerto sino hubiera habido atrás todo el desmadre (sic): cuando los granaderos hace años entraron golpeando a toda la gente que veían; cuando el conflicto de la carretera, o sea, no hubiera sido lo mismo si no hubiese un acumulado de cosas que aquí, cuando el conflicto del aeropuerto, vinieron a enchufar muy bien, ¿no? (Del Valle, 2006).

En el caso del actor atenquense, resulta notorio cómo el agravio es un elemento que está presente. No obstante, es necesario no incurrir en lecturas deterministas y monocausales: no todos los individuos que se han sentido agraviados alguna vez han decidido movilizarse. Por lo tanto, la participación en un movimiento social supone un proceso decisorio en donde no basta con sentirse agraviado, resulta preciso, también, que los actores sociales identifiquen las causas de dicho agravio, así como el hecho de que los actores se asuman, se reconozcan como agentes, como habilitados para incidir, y por tanto transformar, aquellos acontecimientos que han sido socialmente definidos como un problema o como una necesidad.

De manera semejante, es importante aclarar quesi bien el sentimiento de agravio puede ser experimentado de forma individual, siempre se sustenta en un marco normativo, en una concepción socialmente erigida sobre lo justo e injusto, lo legítimo e ilegítimo. Esta línea axiológica fue explorada por Edward Palmer Thompson al afirmar cómo los valores constituyen una dimensión vivencial y cómo están condicionados 
por elementos culturales e históricos. Es así como Thompson, elabora su concepto de conciencia afectiva y moral, la cual está anclada en la misma vida material de los actores sociales:

[L]os valores no son pensados ni pronunciados: son vividos y surgen en los mismos nexos de la vida material y de relaciones materiales que nuestras ideas. Son las necesarias normas, reglas, expectativas, etcétera, aprendidas (y aprendidas en nuestros sentimientos) en el marco del habitus del vivir y aprendidas en primer lugar en el seno de la familia, en el trabajo y en el interior de la comunidad inmediata. Sin este aprendizaje, la vida social no podría sostenerse y toda producción cesaría [...]. Un examen materialista de los valores debe situarse no junto a proposiciones idealistas, sino frente a la morada material de la cultura: el modo de vida de las personas y, sobre todo, sus relaciones productivas y materiales (Thompson, 1981: 268-269. Cursivas mías).

Como se expuso anteriormente, aquellos ejidatarios y residentes de las comunidades afectadas por la expropiación tuvieron como adversarios no sólo al gobierno federal, al estatal y al local, sino también a un sector de la comunidad que estaba dispuesto a vender sus tierras. Subyacente a este conflicto se encontraba el enfrentamiento de dos marcos normativos, es decir, la decisión entre vender o no la tierra significaba una elección de valores. En todo este proceso, los integrantes de la movilización atenquense definieron axiológicamente tanto a sus adversarios como a ellos mismos. Así, el juicio moral sobre el otro implicaba no sólo su desacreditación, sino también la autolegitimación de la propia lucha atenquense:

Ellos, los priistas nos vendieron, todo lo que tienen es gracias a nuestro sufrimiento, las consecuencias que padecimos fueron resultado de lo que ellos provocaron, que ellos negociaron. No podemos perdonar, yo al menos no puedo perdonar a una gente que me iba a arrebatar todo: 
Edith KurI PInEda

mi casa, el patrimonio de mis hijos, el patrimonio de mis padres, porque de haberse hecho efectivo el decreto expropiatorio, ¿dónde estarían mis padres ahorita? Yo no podía permitir todo esto [... ] (Morales, 2006).

Pero, ¿en qué se sustentaba este sentimiento de agravio? A partir de criterios estrictamente analíticos, podemos sostener que una de las razones se relacionaba con el hecho de que la expropiación representaba una enorme amenaza para el patrimonio de miles de atenquenses: "EI gobierno fue injusto con nosotros, pues nosotros no le pedíamos nada. Ya teníamos un patrimonio hecho: un cuarto donde estar, un trabajo, todo esto nos había costado y el gobierno nos lo quería arrebatar y nos lastimó, y lo sigue haciendo, y así como yo hay muchas personas que no estamos bien" (I bíd.).

Así, los ejidatarios y residentes organizados defendieron sus casas y sus ejidos, una fuente de trabajo y de identidad colectiva, así como una forma de reproducción social - material y simbólica - corporeizada en el territorio. Estos elementos, se conjugaron con otras razones que redundaron en dicho sentimiento de agravio, tales como el sufrimiento de seres queridos ante la incertidumbre generada por la expropiación.

Bajo este mismo argumento, afirmo que otra de las fuentes de agravio más notables se vincula con el hecho de que las comunidades afectadas por los decretos expropiatorios jamás hayan sido informadas de manera consistente sobre los alcances que el proyecto aeroportuario tendría, así como el hecho de que jamás hayan sido consultadas por las autoridades gubernamentales. ${ }^{9}$ Desde la perspectiva analítica aquí planteada, esta fuente de agravio e indignación se relaciona con la propia relación de mando-obediencia, con la relación entre gobernantes y gobernados.

Ya en su esfuerzo teórico por encontrar los rasgos transhistóricos de la obediencia y la rebelión, Barrington Moore señaló que todo sentimiento de injusticia y agravio se finca en la existencia de códigos

${ }^{9}$ Esta fue una de las razones comúnmente encontradas en el trabajo decampo desarrollado en los pueblos de San Salvador Atenco, Acuexcómac y N exquipayac. 
morales, o sea, no es posible hablar del agravio sin que haya un conjunto de reglas sociales que hayan sido conculcadas. Para este pensador, uno de los orígenes del sentimiento de injusticia más común parte, precisamente, del resquebrajamiento del contrato social, implícito o no, que regula toda relación de mando-obediencia. Dicho contrato es un constructo en donde los sectores dominantes deben dar protección a los sectores subalternos a cambio de que éstos reconozcan y acaten su autoridad. Para Moore, esta relación de reciprocidad se distingue por ser un acuerdo que siempre está sujeto a (re)negociaciones, por ser una construcción no acabada:

En cualquier sociedad estratificada hay un conjunto de límites sobre lo que pueden hacer tanto quienes ponen las reglas como quienes las obedecen, es decir los grupos dominantes y los subordinados. También hay un conjunto de obligaciones mutuas que unen a los dos. Estos límites y obligaciones no están establecidos en constituciones formales ni en contratos escritos, pero en las sociedades que sí tienen esa parafernalia se pueden establecer algunas de esas especificaciones, aunque no necesariamente las más importantes [...]. Lo que sin embargo sucede es la continua indagación, por parte de los dirigentes y de sus súbditos para encontrar cómo salirse con la suya, es decir, que ponen a prueba y descubren los límites de la obediencia y la desobediencia, límites que nadie sabe cuáles son exactamente, hasta que los descubre por la experiencia, si bien ambas partes pueden anticiparlos con bastante exactitud (Moore, 1996: 30).

De forma sintética se puede señalar, a partir de criterios meramente analíticos, que las razones por las cuales los atenquenses movilizados se sintieron agraviados ante la expropiación son tanto de índole privada como pública. Tal como se ha mostrado, los decretos expropiatorios fueron leídos por los integrantes de la lucha en contra del aeropuerto como una decisión ilegítima y unilateral, una decisión que, desde esa lectura, trastocaba una implícita noción sobre el bien común. 
Edith Kuri Pineda

A MODO DE CIERRE

Tal como se ha visto a lo largo de este artículo, el proceso intersubjetivo de construcción de sentido en un escenario de movilización social constituye una veta de exploración teórica y empírica clave para comprender el por qué y el cómo se gestan los actores colectivos. En el caso de la lucha atenquense, la labor de enmarcado efectuada por sus miembros se centró en subrayar el despojo de sus tierras y la defensa de una forma de subsistencia material y simbólica, tal como algunos de ellos lo han expresado al enarbolar el machete como un emblema de trabajo y de identidad. Este trabajo de enmarcado fue, asimismo, realizado por los adversarios de este movimiento social, el gobierno federal, el estatal y el municipal, quienes desde el inicio del conflicto enfatizaron que el proyecto aeroportuario implicaría progreso y modernización. El campo de confrontación sociopolítica y jurídica tejido por los ejidatarios y sus adversarios revela cómo, subyacente a toda disputa política, se encuentra una lucha por el sentido. Asimismo, las posturas divergentes en torno a las formas en que se podía revertir la expropiación sostenidas, por una parte, por Atenco Unido y, por lo que más tarde conoceríamos como el Frente de Pueblos en Defensa de la Tierra (FPDT), por la otra, muestra también dos marcos de pronóstico diferentes: mientras los primeros consideraban que la batalla jurídica era suficiente para frenar los decretos expropiatorios, los segundos interpretaban que la movilización social era indispensable para lograr dicho fin. La diferencia entre ambos grupos posibilita inferir cómo la construcción de toda acción colectiva está marcada por un intenso proceso de disputa y negociación interna, dimensión que debe ser abordada analíticamente.

Reconocer, por otra parte, la intencional idad inherente a toda acción social supone referirse a la experiencia, a la experiencia vivida y significada por los propios actores. En el caso de la resistencia en contra del aeropuerto, resulta claro que su constitución no obedeció a una sumatoria de acciones espontáneas, improvisadas e irreflexivas, sino que por el contrario, antes de este conflicto sociopolítico existía en esta zona mexiquense una densidad organizativa y política acuñada desde años atrás. En otras palabras, los antecedentes de organizaciones sociales encauzadas a gestionar distintas demandas sociales, junto con la experiencia 
organizativa labrada a partir de la cel ebración de fiestas y faenas forjaron un acervo de conocimientos sociopolíticos, al cual los atenquenses "recurrieron" una vez promulgados los decretos expropiatorios. LoS repertorios de confrontación desplegados durante el conflicto aeroportuario como marchas, bloqueos carreteros, retención de funcionarios gubernamentales, plantones, eran "métodos de lucha" empleados tiempo atrás, en otros contextos de movilización social. Ante la incertidumbre generada por el proyecto aeroportuario, los atenquenses inconformes "echaron mano" de lo que sabían hacer y que reconocían como formas potencialmente eficaces para frenar lo que ellos interpretaban como un inminente despojo.

El acervo de conocimientos sociopolíticos, las redes sociales de reciprocidad intra e intercomunitarias junto con la existencia de un memorial de despojo y agravios fueron delineando al movimiento social en contra del aeropuerto. La resistencia en contra de los diecinueve decretos expropiatorios, y sobre todo el haber conseguido abrogarlos constituye, sin duda alguna, otra fuente de experiencia sociopolítica, otro referente de significados. Es así como, una vez anulado el proyecto aeroportuario, un sector del FPDT optó por seguir participando políticamente con un trabajo apartidista encaminado a gestionar diferentes demandas sociales provenientes de una serie de comunidades mexiquenses, de nueva cuenta desplegando aquellos repertorios de confrontación que han sido su sello distintivo. Fue bajo ese nuevo escenario de organización social que se dieron los acontecimientos del 3 y el 4 de mayo de 2006, otro parteaguas fundamental en la historia de estos pueblos. El notable reto que los atenquenses enfrentan hoy en día no sólo se refiere a la liberación de los presos políticos sino también lograr (re)articular el entramado social, aquel desde el cual fue erigida la defensa del territorio.

Así, un desafío relevante para el investigador social radica, precisamente, en explorar la dimensión interpretativa y axiológica presente en los movimientos sociales, en rastrear aquellos componentes históricos, políticos, culturales y vivenciales que perfilan el sentido que le dan los actores a su propia acción y que en muchas ocasiones pueden ser sentimientos de agravio e injusticia. Los puntos trabajados a lo largo de este artículo remiten a pensar la importancia que revisten los 
procesos de constitución y transformación de la subjetividad colectiva ante una coyuntura de movilización. La realidad social, una vez más, nos ofrece nuevas preguntas.

REFERENCIAS BIBLIOGRÁFICAS

Alcayaga, C. (2002), Atenco: el peso del poder y el contrapeso de la resistencia civil, México: Porrúa.

Estrada, M. (1995), Participación política y actores colectivos, México: Universidad Iberoamericana-Plaza y Valdés.

GidDENs, A. (1998), La constitución de la sociedad. Bases para la teoría de la estructuración, Buenos Aires: Amorrortu.

Gilly, A. (2006), Historia a contrapelo. U na constelación, México: Era.

Gramscl, A. (1981), Cuadernos de la cárcel, tomo 6, México: EraBenemérita Universidad Autónoma de Puebla.

Meluccl, A. (1991), "La acción colectiva como construcción social", en Estudios Sociológicos, volumen 9, número 26, mayo-agosto de 1991, México: El Colegio de México, pp. 357-364.

--- (1994), "Asumir un compromiso: identidad y movilización en los movimientos sociales", en Zona Abierta, núm. 69, Madrid: Fundación Pablo Iglesias, pp. 153-180.

---- (2002), Acción colectiva, vida cotidiana y democracia, México: El Colegio de México.

Moore, B. (1996), La injusticia, bases sociales de la obediencia y la rebelión, México: UNAM.

Schutz, A. y Luckmann, T. (1997), Las estructuras del mundo de la vida, Buenos Aires: Amorrortu.

Scott, H., Benford, R. y Snow, D. (2006), "M arcos de acción colectiva y campos de identidad en la construcción social de los movimientos sociales", en Aquiles Chihu (coord.), El análisis de los marcos en la sociología de los movimientos sociales, México: Universidad Autónoma Metropolitana (UAm)-Iztapalapa, pp. 155-188.

TARrow, S. (1997), El poder en movimiento. Los movimientos sociales, la acción colectiva y la política, Madrid: Alianza. 
El movimiento social de Atenco: experiencia y construcción de sentido

Thompson, E. P. (1981), Miseria de la teoría, Barcelona: Crítica.

TILLY, C. (1978), From movilization to revolution, Chicago: Addison Wesley.

Touraine, A. (1995), Producción de la sociedad, México: Instituto Francés de América Latina (IFAL)-UNAM.

Zemelman, H. y Valencia, G. (1990), "Los sujetos sociales, una propuesta de análisis", Acta Sociológica, vol. 3, número 2, mayo-agosto, México: uam Azcapotzalco, pp. 89-104.

ZIBECHI, R. (2005-2006), "Espacios, territorios y regiones: la creatividad social de los nuevos movimientos sociales en América Latina", en Contrahistorias. La otra mirada de Clío, año 3, número 5, septiembre-febrero, Morelia: Jitanjáfora, pp. 39-60.

ENTREVISTAS CITADAS

Del Valle, América (2006), realizada por la autora en el pueblo de San Salvador Atenco el 26 de marzo. Archivo personal, Edith Kuri Pineda (EKP).

Morales, Josefina, (2006), realizada por la autora en el pueblo de San Salvador Atenco el 12 de febrero. Archivo personal, EKP.

Robles, Ana María (2005), realizada por la autora en el pueblo de San Salvador Atenco el 28 de diciembre. Archivo personal, EKP.

Fecha de recepción: 31 de julio de 2008

Fecha de aceptación: 23 de junio de 2009

Volumen 7, número 14, septiembre-diciembre, 2010, pp. 321-345 Andamios 345 